\title{
Research Paper: Vocational Rehabilitation for Individuals With Substance-Related Disorders
}

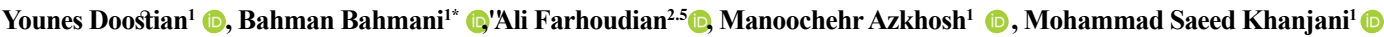

1. Department of Counseling, University of Social Welfare and Rehabilitation Sciences, Tehran, Iran.

2. Substance Abuse and DependencHResearch Center, University of Social Welfare \& Rehabilitation Sciences, Tehran, Iran.

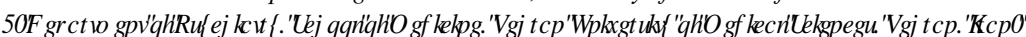

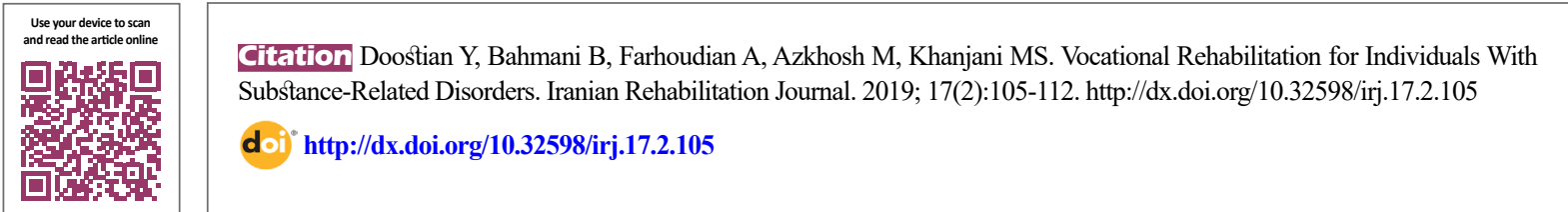

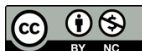

Article info:

Received: 02 Nov 2018

Accepted: 13 Feb 2019

Available Online: 01 June 2019

\section{Keywords:}

Vocational rehabilitation, Substance-related disorders, Substance addiction

\section{ABSTRACT}

Objectives: The present review study aimed at investigating the vocational rehabilitation of individuals with drug dependence disorders.

Methods: Based on the research method, a comprehensive search was conducted in the following databases: PubMed, Scopus, Web of Science, Science Direct, EBSCO, ProQuest and Google Scholar. All keywords synonymous with vocational rehabilitation and substance abuse were considered in search. Then related studies with vocation rehabilitation were selected and included in the study.

Results: Job is a protective and major factor in effective treatment, and ignoring vocational counseling and rehabilitation leads to a significant defect in addiction treatment.

Discussion: Individuals receiving vocational services along with drug abuse treatment would experience reduced drug abuse and a more productive life. 


\section{Highlights}

- One of the strongest predictors of effective treatment and long-term avoidance after addiction treatment is to achieve successful employment.

- There is a significant relationship between increasing occupational activity and reducing drug use.

- Successful treatment should resolve occupational issues.

\section{Plain Language Summary}

Unemployment is one of the challenges faced by people with drug-related disorders so that even standard treatments are less likely to be employed after treatment . However, successful treatment and long-term avoidance alone cannot guarantee that the former addict can find a job suitable to his or her condition or will be employed. So these former addicts need to receive special care services. The occupational rehabilitation program helps people with drug-related problems to get a decent job by recognizing their individual needs and referring to appropriate services. Job rehabilitation helps individuals develop a realistic perspective on their skills, abilities, and limitations, as well as coping skills, and other competencies.

\section{Introduction}

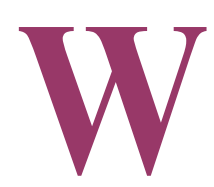

orld is faced with various human challenges one of which is unemployment that is one of the factors for initiation and expansion of addiction [1]. In fact, it can be said that having a job is uncommon for most drug abusers [2]. Previous researches show that drug abuse among unemployed individuals is higher than the ones with a fixed job.

Vaillant suggested that $80 \%$ of 40 -year-old individuals dependent on heroin in New York are unemployed [3]. Also, Maddux and McDonald found 21\% employment rate among individuals dependent on heroin in Texas [4]. Generally, it can be stated that, employment rate among drug dependent individuals is as low as $15-35 \%$ [5]. This high rate of drug abuse among unemployed individuals compared to the employed population can be an important alarming factor to identify treatment needs and prevent drug abuse [6].

It can be argued that the relationship between vocation and treatment of addiction is a two-way relationship in which vocation can affect both the reduction of drug abuse and its treatment, and successful treatment leads to the person being employed after treatment. However, employment is not a priority in most drug addiction recovery programs, which leads to instability in treatment in this population. On the other hand, no study shows the various aspects of the vocational rehabilitation of this group. Therefore, with this background in mind, the present review study was performed to assess the available evidence with regard to the relationship between vocational rehabilitation and treatment in individuals with drug dependence disorders.

\section{Methods}

The current study explored related researches with vocational rehabilitation in people with substance abuse disorders. Based on the research method, a comprehensive search was conducted in the following databases: PubMed, Scopus, Web of Science, Science Direct, EBSCO, ProQuest, and Google Scholar. All keywords synonymous with vocational rehabilitation and substance abuse were considered in the search. Then, related studies with vocation rehabilitation were selected and included in the study.

Next, contents of the titles and abstracts of the selected studies were reviewed. Articles based on the being of a search word in the title or keywords, publication in scientific journals, and including patients with no previous psychiatric disorders were selected for the ultimate report. Finally, all contents of the selected articles were carefully studied. In the next step, the sources of selected articles were also studied, and if they were related to the research, they were added to the selected articles.

\section{Results}

The results obtained from reviewing the literature on occupational rehabilitation can be reviewed and presented in several categories. 


\section{Job and addiction treatment}

\section{Vocational status and retention in treatment}

Unemployment is common among drug abusers and leads to weak treatment outcomes such as withdrawal from treatment, higher use of drugs during treatment, and higher rate of relapse [7]. McLellan stated a positive and significant relationship between vocational status and retention in treatment [8]. Also, Webster et al. concluded that individuals with a fixed job or employment after treatment, pursue the treatment procedures with more enthusiasm and, therefore, avoid drug abuse for longer periods [9].

Ti et al. indicated that the first and most important factor related to treatment withdrawal was having no fixed job [10]. Accordingly, it can be concluded that employment leads to improvement in treatment outcomes [11], retention in treatment and longer avoidance of drug abuse [12], lower rate of relapse and more cooperation and higher motivation for improvement in treatment programs [13], and ignoring this important matter is a big defect in the treatments of the patients with no plan for employment.

\section{The role of job in treatment effectiveness}

One of the most powerful predictive factors of effective treatment and long-term avoidance after treatment is attaining a successful employment [14]. In this regard, Preble and Casey stated that employment can be considered as a major element in the success of addiction treatment outcome, and through this treatment dimension. Individuals can maintain their improvement motivation and avoid drug abuse for longer periods [15].

Walls et al. confirmed that employment is of high importance in successful treatment of drug abusers, and offering vocational services among individuals seeking for addiction treatment is highly important [16]. Platt showed that literature of drug abuse and occupation suggests three general points: 1 . employed individuals have lower rate of drug abuse compared to the unemployed ones or with temporary jobs; 2 . individuals seeking addiction treatment often have high rates of unemployment or methemoglobin; and 3. successful treatment outcome (like full improvement, long-term avoidance) is related to the increase in individuals' employment [2].

In this regard, Melvin et al. showed that employment is effective on successful and full treatment, and leads to decreased drug abuse [17]. Hereupon and West stat- ed that although there is evidence that occupation is a predictive factor for successful treatment, there are no vocational components in most treatment programs designed for drug abuse; while vocational rehabilitation services may help abusers to find a job and lead to a life style with no drug [14].

Effect of employment on improving psychological status

Unemployment has many destructive effects on individual, family, and society, therefore, it is considered as one of the main causes of psychological disorders [18]. Modini et al. suggested that employment based on individual interests and abilities can facilitate the disease treatment and increase individuals` psychological wellbeing [19].

Addiction leads to physical sufferings in the individuals, it also fades away their hopes and self-esteem and robs him of the growth and dynamic, which every person needs. Past researches clearly show that unemployment among the youth leads to various psychological problems such as depression, anxiety, low self-esteem, alcohol-and-drug-related disorders, and suicide [20]; and this finding means that increasing vocational activities is an important factor to improve psychological status of individuals, and by improving psychological status of addicts, a more effective and thorough treatment would be possible [21].

Employment as an important component of treatment and key element of rehabilitation

Various efforts are made to prevent, treat, and avoid addiction relapse in individuals by administrative authorities, non-governmental organizations, and therapists, but it can be said that employment is a facilitator in attaining success to treat this social problem. In fact, employment is an important factor in addiction treatment [22].

Platt believes that in addiction treatment, employment can be considered as both a treatment outcome and a major treatment element [2]. Therefore, employment can be considered as a reward and a phase in the recovery process of drug abusers [23].

Melvin et al. considers the employment of addict individuals after treatment as a supplement to drug abuse treatment [17]. In this regard, some researches consider employment as a predictive factor for a successful treatment [14]. Also, Ginexi et al. stated that many drug abusers gain the ability to attain a job after treatment; this means that if vocational services are considered as a major factor in addiction treat- 
ment, the treatment would be successful and individuals would be more committed to treatment and participation in treatment process, as well [7].

Employment as an index of improvement and addiction treatment goal

Drug abuse also negatively affects life and occupation of individuals, brings about various problems for employed individuals, and in some cases leads to losing one's job or getting harmed during work [24]. Therefore, employment is considered as the goal of addiction treatment and a treatment outcome in some researches [2]; and some therapists believe that employment has a critical role in improving drug-dependent individuals and can lead to their full treatment and prevention of their relapse; in this regard, Magura et al. argue that if one important goal of addiction treatment is the individual's employment, then vocational rehabilitation should have a particular place in treatment programs in order that the person can find an appropriate job after rehabilitation, and he/she would have a longer retention in treatment (through the protective power of employment) [25].

The role of unemployment in drug abuse and expansion of addiction

Unemployment is common among drug abusers and leads to poor treatment outcomes such as withdrawal from treatment and increased abuse of drug during treatment [7]. Some researchers argue that unemployment leads to increase in addiction rate and prevalence of psychological problems in different ways [26]. Mehrazma et al. also said that unemployment and separation from family are among the most important factors for the tendency of individuals to addiction [27].

In sum, it can be said that employment is associated with reduced severity of drug abuse disorders before treatment, shorter period of addiction and drug abuse, and lower rate of drug abuse related consequences [2]. Unemployment or methemoglobin are reversely related with frequent and heavy drug abuse, long-term history of abuse, and many other consequences [25].

The effect of employment on prevention of relapse

Having an appropriate job is one of the most important factors and opportunities of staying clean after quitting and his return to society, and in case of lack of this opportunity, the addiction relapse happens very quickly [7]. In fact, employment can be considered as a protective factor against drug abuse relapse; in this regard, Webster et al. stated that employment is an important component of drug abuse treatment, a predictive factor for retention in treatment, and a hopeful element for reducing relapse [9].

Overall, job is accepted as a pre-treatment protective factor which leads to both retentions in treatment and prevention from relapse [8]. Magura et al. found that participants that were employed or obtained a job during the treatment, showed lower rate of relapse compared to the unemployed ones [25]. Therefore, while employment after treatment doesn't guarantee the avoidance of drug abuse after treatment, evidence shows that individuals not engaged with constructive roles such as job or education, have higher risk for relapse [28].

Duffy and Baldwin in their research aimed at investigating the risk factors for relapse concluded that social support and employment are among important issues to prevent relapse after treatment [29]. Accordingly, it can be said that unemployment during avoidance of drug abuse is one of the main reasons for relapse; therefore, regular follow-up by the therapist and social-family support accompanied by vocational rehabilitation are necessary to prevent relapse [30].

\section{Employment as a means of returning to society and social integration}

The self-confidence of individuals improves after engaging with vocational activities, they return to their social environment and take a constructive role in society, which leads to the increase of their commitment to treatment [31]. Platt believes that employment of the addict after or during the treatment is a means of his return to society and integration in his social environment, which leads to improvement of his motivation and higher retention in treatment, and this protects him as a healthy individual [2].

Generally, therapists consider employment as a gateway to new, healthy, and productive social/professional relationships for drug abusers, through which the individual regains his self-esteem and social position, and benefits from social support for better improvement [32].

\section{The effect of employment on reducing drug abuse} and commitment of crime acts

Addiction imposes many expenses on families, and due to reducing economic activities of the addict and also his increasing need to buy drugs, leads the individuals towards criminal acts. Results of previous research on the impor- 
tance of employment for addicts shows a lower rate pf relapse and criminal acts after their employment [33]. In this regard, Coviello et al. emphasized on the importance of integrating vocational counseling components in treatment of drug abuse [34]. These researchers reported that employment reduces drug abuse, the rate of criminal acts, and highrisk behaviors. In other words, having a job leads to earning money from legal ways and also improving self-esteem in the individual, which finally leads to reduced drug abuse and criminal activities [31].

Setbacks of employment in drug-dependent individuals

The fact is that having just one addiction background, even after months or years, would be accompanied by career problems [35]. Although employment has a positive relationship with other indices of successful treatment, drug abusers often face setbacks to find and maintain a job. These individuals often have weak vocational habits such as frequent absence, delay, sleeping at work, and using indecent and obscene language at work environment [36], and experience difficulties in staying organized, controlling stress, emergency meetings and maintaining endurance during work [16]

Therefore, drug-dependent individuals have problems to find a job or return to their prior job, and the obtained results of such researches indicate that to find a job drug abusers face setbacks such as weak vocational record due to imprisonment, the stigma related to penal record, and labels such as drug abuser [37]. Therefore, the available jobs for drug abusers are often with low income and they are unprofessional [9]. Moreover, these individuals might have an immature career identity, particularly if drug abuse happens before they get employed, therefore drug users might not learn necessary skills related to a job or necessary behaviors to achieve a career [37].

Hence, desirable treatment procedure for drug-related disorders should start with detoxification and be followed up by rehabilitation services, and along with/or after rehabilitation plans, prevention of relapse should be considered [38], and this important issue is attainable through vocational trainings along with treatment, obtaining necessary vocational skills and procuration of employment, and eventually through appropriate employment.

\section{Discussion}

Stigma or label of addiction would be the first step towards fading away the confidence of employers to em- ploy drug-dependent individuals or recovered addicts. In the view of public, addiction of the individual means that he cannot stick to his obligations, and to earn the expenses of buying drugs possibly does actions that would threaten the position of his employer. Hence, helping these individuals to return to normal life in the frame of providing services such as residence and employment can prevent their tendency to get back to drug abuse, or at least, it can reduce its risk. If the drug-dependent individuals obtain a job appropriate to their talents and abilities during treatment, it would lead to more retention in treatment, reduced drug abuse, and reduced criminal acts and high-risk behaviors [34]. Therefore, job is a protective and major factor in effective treatments and ignoring vocational counseling/rehabilitation is a considerable defect in addiction treatment.

Although vocational rehabilitation in addiction treatment is a therapeutic goal and reward, it is faced with setbacks that make this process difficult. Among personal setbacks, lack of vocational skills can be noted in which the individual obtains no especial skill to engage with any jobs or he has a weak and limited vocational background. It can be proposed that employment provides a combination of interpersonal (e.g. self-esteem), interpersonal (e.g. socialization), and environmental (such as structure) advantages for the drug-dependent individual, which lead to avoidance of drug abuse and overall improvement in functions of the individual [3].

Finally, it is suggested that systematic review of occupational rehabilitation models in this population be investigated in future studies. Also, studies that explain the process of vocation rehabilitation in such people could be very fruitful.

\section{Conclusion}

In recent years, although rehabilitation centers provide various services to addicts in primary phases of treatment and for their healthy return to society, lack of efficient organizations to help these individuals for retention in treatment leads to their quick return to addiction. Overall, when drug abuse treatment is combined with supplementary services related to employment, it has a direct relationship with the individual's function after treatment and forms a protective factor after treatment, which makes the individual see his health status in priority and stay away from the cycle of drug abuse and addictive patterns. 


\section{Ethical Considerations}

\section{Compliance with ethical guidelines}

There was no ethical considerations to be considered in this research.

\section{Funding}

This research did not receive any specific grant from funding agencies in the public, commercial, or not-forprofit sectors.

\section{Authors' contributions}

Conceiving the research question, designing the review: All authors; Providing guidance for the evaluation of vocation rehabilitation models in people with substance-related disorders: Ali Farhoudian; Performing the literature search, testing, and revising the electronic search strategy: Younes Doostian, Bahman Bahmani; Designing the statistical analysis plan: Manoochehr Azkhosh, Mohammad Saeed Khanjani; and Writing and revising the manuscript, making substantial contributions to the conception and design of the paper, piloting the inclusion criteria, providing direction to the data extraction and analysis, Reading and approving the final manuscript: All authors.

\section{Conflict of interest}

The authors declared no conflict of interest.

\section{References}

[1] Naqshb MM. [Drug addiction and youth of Kashmir. International NGO Journal. 2012; 7(5):84-90.

[2] Platt JJ. Vocational rehabilitation of drug abusers. Psychological Bulletin. 1995; 117(3):416-433. [DOI:10.1037/00332909.117.3.416] [PMID]

[3] Vaillant GE. A twelve-year follow-up of New York narcotic addicts: IV. Some characteristics and determinants of abstinence. American Journal of Psychiatry. 1966; 123(5):573-85. [DOI:10.1176/ajp.123.5.573] [PMID]

[4] Maddux JF, McDonald LK. Status of 100 San Antonio addicts one year after admission to methadone maintenance. Drug Forum, 2(3), 239-52.

[5] Sigurdsson SO, DeFulio A, Long L, Silverman K. Propensity to work among chronically unemployed adult drug users. Substance Use \& Misuse. 2011; 46(5):599-607. [DOI:10.3109/ 10826084.2010.526982] [PMID] [PMCID]
[6] Henkel D. Unemployment and substance use: A review of the literature (1990-2010). Current Drug Abuse Reviews. 2011; 4(1):4-27. [DOI:10.2174/1874473711104010004] [PMID]

[7] Ginexi EM, Foss MA, Scott CK. Transitions from treatment to work: Employment patterns following publicly funded substance abuse treatment. Journal of Drug Issues. 2003; 33(2):497-518. [DOI:10.1177/002204260303300210]

[8] McLellan AT, Luborsky L, O'brien CP, Barr HL, Evans F. Alcohol and drug abuse treatment in three different populations: Is there improvement and is it predictable? The American Journal of Drug and Alcohol Abuse. 1986; 12(1-2):101-20. [DOI:10.3109/00952998609083746] [PMID]

[9] Webster JM, Staton-Tindall M, Dickson MF, Wilson JF, Leukefeld CG. Twelve-month employment intervention outcomes for drug-involved offenders. The American Journal of Drug and Alcohol Abuse. 2014; 40(3):200-5. [DOI:10.3109/009 52990.2013.858722] [PMID]

[10] Ti L, Milloy M, Buxton J, McNeil R, Dobrer S, Hayashi K, et al. Factors associated with leaving hospital against medical advice among people who use illicit drugs in Vancouver, Canada. PLOS One. 2015; 10(10):e0141594. [DOI:10.1371/ journal.pone.0141594] [PMID] [PMCID]

[11] Vaillant GE. A 20-year follow-up of New York narcotic addicts. Archives of General Psychiatry. 1973; 29(2):237-41. [DOI:10.1001/archpsyc.1973.04200020065009] [PMID]

[12] Hser YI, Hoffman V, Grella CE, Anglin MD. A 33-year follow-up of narcotics addicts. Archives of General Psychiatry. 2001; 58(5):503-8. [DOI:10.1001/archpsyc.58.5.503]

[13] Lundgren LM, Schilling RF, Ferguson F, Davis K, Amodeo M. Examining drug treatment program entry of injection drug users: Human capital and institutional disaffiliation. Evaluation and Program Planning. 2003; 26(2):123-32. [DOI:10.1016/ S0149-7189(03)00013-2]

[14] West SL. The utilization of vocational rehabilitation services in substance abuse treatment facilities in the US. Journal of Vocational Rehabilitation. 2008; 29(2):71-5.

[15] Preble E, Casey JJ. Taking care of business-the heroin user's life on the street. International Journal of the Addictions. 1969; 4(1):1-24. [DOI:10.3109/10826086909061998]

[16] Walls RT, Moore LC, Batiste LC, Loy B. Vocational rehabilitation and job accommodations for individuals with substance abuse disorders. Journal of Rehabilitation. 2009; 75(4):35-44

[17] Melvin AM, Davis S, Koch DS. Employment as a predictor of substance abuse treatment. Journal of Rehabilitation. 2012 78(4):31-7.

[18] Paul KI, Moser K. Unemployment impairs mental health: Meta-analyses. Journal of Vocational behavior. 2009; 74(3):264-82. [DOI:10.1016/j.jvb.2009.01.001]

[19] Modini M, Tan L, Brinchmann B, Wang MJ, Killackey E, Glozier N, et al. Supported employment for people with severe mental illness: Systematic review and meta-analysis of the international evidence. British Journal of Psychiatry. 2016; 209(1):14-22. [DOI:10.1192/bjp.bp.115.165092] [PMID]

[20] Marmot M, Bloomer E, Goldblatt P. The role of social determinants in tackling health objectives in a context of economic crisis. Public Health Reviews. 2013; 35:9. [DOI:10.1007/ BF03391694] 
[21] Hammer T, Ravndal E, Vaglum P. Work is not enough: A quasi-experimental study of a vocational training programme for young drug and alcohol abusers. Journal of Drug Issues. 1985; 15(3):393-403. [DOI:10.1177/002204268501500308]

[22] Holtyn AF, DeFulio A, Silverman K. Academic skills of chronically unemployed drug-addicted adults. Journal of Vocational Rehabilitation. 2015; 42(1):67-74. [DOI: 10.3233/JVR-140724]

[23] Waldorf D, Biernacki P. The natural recovery from opiate addiction: Some preliminary findings. Journal of Drug Issues. 1981; 11(1):61-74. [DOI:10.1177/002204268101100104]

[24] Slaymaker VJp. Vocational impact of drug abuse and addiction. In: JC. Verster, k. Brady, M. Brady. P. Conrod, editors. Drug Abuse and Addiction in Medical Illness. Berlin: Springer; 2012. [DOI:10.1007/978-1-4614-3375-0_43]

[25] Magura S, Staines GL, Blankertz L, Madison EM. The effectiveness of vocational services for substance users in treatment. Substance Use \& Misuse. 2004; 39(13-14):2165-213. [DOI:10.1081/JA-200034589]

[26] Cheung S, Marriott B. Impact of an economic downturn on addiction and mental health service utilization: A review of the literature. Alberta Health Services, Knowledge notes num. 12 [Internet]. 2015 [Cited 7 December 2015]. Available from: https://www.albertahealthservices.ca/assets/info/ $\mathrm{res} / \mathrm{mhr} /$ if-res-mhr-kn-12-economic-downturn.pdf

[27] Ahmadi K, Mehrazma A, Karambakhsh A, Salesi M. [An investigation of demographic and familial characteristics of addicted soldiers (Persian)]. Journal of Military Medicine. 2013; 15(3):201-8.

[28] Hawkins JD, Catalano RF. Aftercare in drug abuse treatment. International Journal of the Addictions. 1985; 20(67):91745. [DOI:10.3109/10826088509047759] [PMID]

[29] Duffy P, Baldwin H. Recovery post treatment: Plans, barriers and motivators. Substance Abuse Treatment, Prevention, and Policy. 2013; 8:6. [DOI:10.1186/1747-597X-8-6] [PMID] [PMCID]

[30] Sau M, Mukherjee A, Manna N, Sanyal S. Sociodemographic and substance use correlates of repeated relapse among patients presenting for relapse treatment at an addiction treatment center in Kolkata, India. African Health Sciences. 2013; 13(3):791-9. [DOI:10.4314/ahs.v13i3.39] [PMID] [PMCID]

[31] Kerrigan AJ, Kaough JE, Wilson BL, Vaughn Wilson J, Bostick R. Vocational rehabilitation of participants with severe substance use disorders in a VA veterans industries program. Substance Use \& Misuse. 2004; 39(13-14):2513-23. [DOI:10.1081/JA-200034695]

[32] Comerford AW. Work dysfunction and addiction: Common roots. Journal of Substance Abuse Treatment. 1999; 16(3):247-53. [DOI:10.1016/S0740-5472(98)00070-1]

[33] Faupel CE. Heroin use, crime and employment status. Journal of Drug Issues. 1988; 18(3):467-79. [DOI:10.1177/002 204268801800311]

[34] Coviello DM, Zanis DA, Wesnoski SA, Domis SW. An integrated drug counseling and employment intervention for methadone clients. Journal of Psychoactive Drugs. 2009; 41(2):189-97. [DOI:10.1080/02791072.2009.10399912] [PMID]

[35] Laudet $A B$, White $W$. What are your priorities right now? Identifying service needs across recovery stages to inform ser- vice development. Journal of Substance Abuse Treatment. 2010; 38(1):51-9. [DOI:10.1016/j.jsat.2009.06.003] [PMID] [PMCID]

[36] Carpenedo CM, Needham M, Knealing TW, Kolodner $\mathrm{K}$, Fingerhood M, Wong CJ, et al. Professional demeanor of chronically unemployed cocaine-dependent methadone patients in a therapeutic workplace. Substance Use \& Misuse. 2007; 42(7):1141-59. [DOI:10.1080/10826080701410089] [PMID] [PMCID]

[37] Webster JM, Staton-Tindall M, Duvall JL, Garrity TF, Leukefeld CG. Measuring employment among substance-using offenders. Substance Use \& Misuse. 2007; 42(7):1187-205. [DOI:10.1080/10826080701409800] [PMID]

[38] Min Z, Xu L, Chen H, Ding X, Yi Z, Mingyuang Z. A pilot assessment of relapse prevention for heroin addicts in a Chinese rehabilitation center. The American Journal of Drug and Alcohol Abuse. 2011; 37(3):141-7. [DOI:10.3109/00952990.201 0.538943] [PMID] [PMCID] 
This Page Intentionally Left Blank 